NBER WORKING PAPER SERIES

\title{
REAL INTEREST RATES, CREDIT MARKETS, AND ECONOMIC STABILIZATION
}

Paul Jenkins

Carl E. Walsh

Working Paper No. 1575

\author{
NATIONAL BUREAU OF ECONOMIC RESEARCH \\ 1050 Massachusetts Avenue \\ Cambridge, MA 02138 \\ March 1985
}

Initial work on this paper was done while Jenkins was a Visiting Student at Princeton University. The authors would like to thank Alan Blinder, Pierre Duguay, Rob Johnson, John Kuszczak, John Murray and Steve Poloz for helpful comments on an earlier draft. The research reported here is part of the NBER's research program in Financial Markets and Monetary Economics. Any opinions expressed are those of the authors and not those of the National Bureau of Economic Research or of the Bank of Canada. 
NBER Working Paper \#1575

March 1985

\title{
Real Interest Rates, Credit Markets, and Economic Stabilization
}

\begin{abstract}
$\underline{\text { ABSTRACT }}$
The role of a real interest rate and a credit aggregate as intermediate monetary policy targets are investigated under the assumption of rational expectations. The analysis expands a standard aggregate model to include a credit market and a market determined interest rate on bank deposits. This allows the implications for output stabilization of real interest rate policy to be examined for a wider variety of shocks than normally considered in the literature, as well as allowing a credit aggregate policy to be studied.
\end{abstract}

Paul Jenkins Research Department Bank of Canada Ottawa, Canada KlA OG9 (613) 563-7320
Carl E. Walsh Department of Economics Princeton University Princeton, NJ 08544 (609) 452-4026 
REAL INTEKEST RATES, CREDIT MARKETS, AND ECONOMIC STABILIZATION

1. Introduction

During the 1970 s, monetary authorities in a number of

countries reoriented the conduct of policy toward setting explicit

targets for monecary growth. Two principal criteria of this approach (Friedman [1975]) are that the measure of the money supply be closely related to the policy objective variable - usually nominal income growth - and that the money supply contain reliable information about the future path of this variable. However, instability in estimated money demand equations in the mid-1970s and, more recently, the extent and speed at which innovation has been occurring in financial markets in response to record high interest rates, deregulation, the computerization of the financial industry and other factors ${ }^{1}$ have raised concern about the appropriateness of using wonetary growth targets for short-run policy purposes. Indeed, two consequences of financial innovation can be identified which would suggest (or in some circumstances clearly have indicated) that the aforementioned criteria are not being met.

The first involves the spread of cash management techniques whereby transactions balances are kept at a minimum. This development results in a shift in the relationship between the woney supply and the ultimate policy objective, thereby rendering monetary growth targets less useful unless the changing relationship can be monitored closely. The second involves combining transactions and savings balances, particularly those of the household sector, into an 
all-in-one account which earns a near-market rate of interest. ${ }^{2}$ This developinent introduces an interest-rate-setting decision, or an own-rate, into the relationship between the money supply and the pollcy variable. ${ }^{3}$

Because of these changing circumstances, increasing attention is being focused on the possible role of real interest rates as intermediate targets for monetary policy. 4 In considering real interest rates for purposes of conducting policy, four important issues need to be addressed: (1) what real interest rate measure should be used (Feldstein and Summers [1978 ]), (ii) what ability does the monetary authorlty have to control the real rate (Shiller [1980 ], (iii) what is an appropriate target level, if any, for the real rate, and (iv) what are the consequences of focusing on real interest rates as opposed solely to a monetary aggregate for purposes of setting policy. In this paper, the last three issues are addressed with particular attention being placed on the fourth issue. As an alternative to both monetary aggregates and real interest rates, Friedman [1983] has suggested that the close correlation between nominal income and a credit aggregate be exploited in the design of monetary policy. By incorporating a rudimentary credit market, the model developed here can also examine the role of a credit aggregate as an intermediate target for monetary policy. In the next section, a basic aggregate, rational expectations model is extended to incorporate a market for loans, a 
market determined interest rate on deposits, and a monetary policy rule which permits non-borrowed reserves to deviate from a target path in response to both real interest rate movements and movements in the aggregate quantity of loans. The model is used, in section 3 , to examine the implications of such a policy rule for aggregate output and price stability. Conclusions are summarized in section 4.

2. The Model

This section extends a standard aggregate rational expectations mode1 (McCallum [1980] to incorporate a market for loans and bank reserves. It differs from the recent models of Parkin [1978], Turnovsky [1980] and Benavie and Froyen [1983] by considering policy rules which incorporate responses to a real interest rate and a credit aggregate.

The real side of the economy consists of two equations. The first is a very simple IS relationship determining aggregate demand. This is assumed to take the form (1) $y_{t}=\beta_{o}-\beta_{1} r_{t}+\varepsilon_{t}$ where $y_{t}$ is the logarithm of aggregate output and $r_{t}$ is the real rate of interest on bank loans, the only nonmonetary asset in the model; $\varepsilon_{t}$ is a white noise disturbance term. 
The second equation, which completes the specification of the goods market is an aggregate supply function given by

$$
y_{t}=\bar{y}+q_{1}\left(p_{t}-t_{t-1} p_{t}\right)+u_{t} \cdot
$$

Equation 2 is a Lucas-type aggregate supply equation with $\bar{y}$ and $p_{t}$ denuting the logs of capacity output and the price level respectively. 5 The notation $t-1 x_{t}$ signifies an expectation of a variable $x_{t}$ formed at time $t-1$. This general notation is used througnout the analysis and expectations are assumed to be rational. The disturbance term in (2), $u_{t}$, is assumed to be a white noise process.

The demand for loans is assumed to be inversely related to the real interest rate on loans and positively related to income. This latter effect reflects an assumption that both firms and households increase their demand for loans as aggregate real spending rises. The loan demand equation is then given by

$$
1_{t}-p_{t}=\delta_{0}-\delta_{1} r_{t}+\delta_{t} y_{t}+v_{t}
$$

where $l_{t}$ is the $\log$ of the nominal quantity of loans. Like $u_{t}$ and $\varepsilon_{t}$, $v_{t}$ is taken to be a white noise disturbance term. 
Money demand is specitied in equation (4) as the demand for Dank deposits:

$$
a_{t}-p_{t}=\gamma_{0}+\gamma_{1} i_{d t}-r_{2} i_{t}+\gamma_{3} y_{t}+\psi_{t}
$$

where $d_{t}$ is the $\log$ of the nominal stock of deposits, $i_{d t}$ is the nominal interest rate on deposits, $1_{t}$ is the nominal loan rate and $\psi_{t}$ is a white noise disturbance term.

Banks are assumed to issue loans and deposits and to hold reserves against their deposits. If banks face a downward sloping demand for loans as a function of the interest rate on loans, an upward sloping demand for deposits as a function of $i_{d t}$, and an upward sloping supply of federal funds as a function of the interest rate on federal funds, ift, bank supply of loans will take the form

$$
1_{t}-p_{t}=a_{0}+a_{1} i_{t}-a_{2} i_{d t}-a_{3} i_{f t}+e_{i t}
$$

The supply of depusits is assumed to be

$$
d_{t}-p_{t}=b_{0}+b_{1} i_{t}-b_{2} i_{d t}+b_{3} i_{f t}+e_{2 t}
$$

The demand for reserves by banks will be assumed equal to required reserves; excess reserves are set equal to zero. If the loy of the reserve requirement ratio is $\rho$ and the log of total reserves is $\mathrm{tr}_{\mathrm{t}}$, 
(7) $\quad \operatorname{tr}_{t}=p+d_{t}$.

The supply of reserves has two components: non-borrowed reserves $n_{t}$, the monetary authorities' policy instrument, and borrowed reserves. To represent bank borrowing behaviour, assume the ratio of total reserves (borrowed plus non-borrowed) to non-borrowed reserves is given by

$$
t r_{t}-n b_{t}=c_{0}+c_{1}^{i}+c_{2} i_{d t}+c_{3}^{i} f t+e_{3 t}
$$

Equations (5)-(8) provide a very simple representation of the banking sector. For a discussion of the aerivation of such relationships from a mode $\perp$ of profit maximizing banks, see Benavie and Froyen [1982 ].

To link the real and nominal interest rates on loans, the Fisher equation is assumed to take the form

(9) $\quad i_{t}=r_{t}+{ }_{t} p_{t+1}-p_{t}$.

One key feature of this model is that participants in financial markets are assumed to have current-period aggregate information when fording expectations about the one-period ahead rate of inflation. In the supply function, however, ${ }_{t-1} \mathrm{p}_{t}$ appears. This can be rationalized in terms of one-period wage contracts in the labour market and in terus of quick processing and dissemination of inforwation in financial markets. This feature of the model is incorporated by using $i_{t}-{ }_{t} p_{t+1}+p_{t}$ instead of (the more common) $i_{t}-{ }_{t-1}\left(p_{t+1}-p_{t}\right)$ as the 
real interest rate. As McCallum [1980] has demonstrated, this specification invalidates the policy ineffectiveness proposition characteristic of one class of rational expectations models developed by Sargent and Wallace [1975] and others by making the unconditional variance of the expectational error for $P_{t}$ potentially dependent on policy parameters.

To complete the model, a specification of the monetary authorities' behaviour must be adopted. One formulation of policy is that used by Poole $[1970]$ in which a fixed money stock rule is compared with a fixed nominal interest rate rule. However, Sargent and Wallace $[1975]$ have shown that under such an interest rate rule the price level is indeterminate. ${ }^{6}$ Accordingly, policy will be characterized by a feedback rule for $\mathrm{nb}_{t}$ that allows $\mathrm{nb}_{t}$ to deviate from a (constant) target in response to past fluctuations in the real interest rate from its expected level. In considering a potential role for real interest rates as an internediate target, however, it is important to bear in mind that the monetary authorities cannot arbitrarily tix $r_{t}$ given the model's assumption that aggregate supply equals aggregate aemand. In addition, to capture the role of a credit aggregate in the design of monetary policy, the monetary authorities are assumed to adjust $\mathrm{nb}_{t}$ in response to unanticipated movements in the stock of loans. The feedback rule is assumed to take the form 
(1u)

$$
n b_{t}=w_{0}+m_{1}\left(r_{t-1}-t_{t-2} r_{t-1}\right)+m_{2}\left(1_{t-1}-t-2{ }_{t-1}\right)
$$

where $m_{0}$ denotes the logarithm of the non-borrowed reserves target. ${ }^{8}$ If $\mathrm{m}_{1}=\mathrm{m}_{2}=0$, the authorities act to hold non-borrowed reserves at the targeted level. If $\mathrm{m}_{1} \neq U\left(\mathrm{~m}_{2} \neq 0\right)$, the monetary authorities allow $n b_{t}$ to deviate from $m_{0}$ if, in the previous period, there was an unanticipated movement in the real rate (stock of loans). At the beginning of period $t$, when the monetary authorities are setting $n b_{t}$, $r_{t}$ and $1_{t}$ are not yet observable. Any feedback rule for setting $n_{t}$ can contain only variables observable at the end of $t-1 .{ }^{7}$ If $r_{t-1}$ or $1_{t-1}$ differ from what had, at the beginning of period $t-1$, been expected, the expectational error is viewed as a signal of shocks to the systein. The monetary authorities are assumed to respond to $\left(r_{t-1}-t_{t-2} r_{t-1}\right)$ and $\left(1_{t-1}-t_{t-2}^{1} t-1\right)$, rather than the underlying disturbances $\left(u_{t-1}, v_{t-1}\right.$, etc. $)$ directly. As the intermeaiate target literature has made clear, this leads to suboptimal stabilization policy (Friedran [1975]). However, it is also the case that the relevant class of policies which are likely to actually be followed by central banks, and which have recently been proposed, are more closely captured by a rule such as equation (10) than they are by an optimal feedback rule. 
Obtaining the rational expectations solution to the model is straightforward and the details can be found in the appendix. It is shown there that

$$
P_{t}=\pi_{0}+\pi_{1}^{\prime} \theta_{t}+\pi_{2}^{\prime} \theta_{t-1}
$$

where $\theta_{t}^{\prime}=\left(\varepsilon_{t}, u_{t}, v_{t}, \psi_{t}, e_{1 t}, e_{2 t}, e_{3 t}\right)$ and $\pi_{1}^{\prime}$ and $\pi_{2}^{\prime}$ are $1 \times 7$

vectors of parameters. Using (11), (1), (2), and (3),

$$
r_{t}=\beta_{1}^{-1}\left(\beta_{0}-\bar{y}\right)-\beta_{1}^{-1}\left(\alpha_{1} \pi_{1}^{\prime} \theta_{t}+u_{t}\right)+\beta_{1}^{-1} \varepsilon_{t}
$$

$$
y_{t}=\bar{y}+q \pi_{1}^{\prime} \theta_{t}+u_{t}
$$

$$
\begin{aligned}
1_{t} & =\left(\pi_{0}+\delta_{0}-\delta_{1} \beta_{1}^{-1}\left(\beta_{0}-\bar{y}\right)+\delta_{2} \bar{y}\right)+\left(\pi_{1}^{\prime}+\left(\delta_{1} \beta_{1}^{-1}+\delta_{2}\right) \alpha_{1} \pi_{1}^{\prime}\right) \theta_{t} \\
& +\pi_{2}^{\prime} \theta_{t-1}-\delta_{1} \beta_{1}^{-1}\left(\varepsilon_{t}-u_{t}\right)+\delta_{t} u_{t}+v_{t}
\end{aligned}
$$

Equations (11)-(14) will be utilized in the next section to examine the role of $\mathrm{m}_{1}$ and $\mathrm{m}_{2}$ in stabilizing economic activity.

\section{Policy Analysis}

As a necessary prelude to any analysis of stabilization policy, it must be shown that the policy feedback rule (10) does allow 
the monetary authority to affect the behavior of the economy by its choice of $\mathrm{m}_{0}, \mathrm{~m}_{1}$, and $\mathrm{m}_{2}$. From (12),

$$
\underline{r}_{t}{ }_{t-1} r_{t}=-\beta_{1}^{-1}\left[q_{1} \pi_{1}^{\prime} \theta_{t}-\varepsilon_{t}+u_{t}\right]
$$

Denoting the elements of $\pi_{1}^{\prime}$, by $\pi_{11}, 1=1, \ldots, 7$, the conditional variance of $r_{t}$ can be defined as

$$
\begin{aligned}
& \sigma_{r}^{2}=\beta_{1}^{-2}\left[\left(1-q_{1} \pi_{11}\right)^{2} \sigma_{\varepsilon}^{2}+\left(1+q_{1} \pi_{12}\right)^{2} \sigma_{u}^{2}+q_{1}^{2} \pi_{13}^{2} \sigma_{v}^{2}+q_{1}^{2} \pi_{14} \sigma_{\psi}^{2}\right. \\
& \left.+q_{1}^{2} \pi_{15}^{2} \sigma_{e 1}^{2}+q_{1}^{2} \pi_{16} \sigma_{e 2}^{2}+q_{1}^{2} \pi_{17} \sigma_{e 3}^{2}\right]
\end{aligned}
$$

where $\sigma_{x}^{2}$ denotes the variance of the random variable $x$, and the elements of $\theta$ are assumed to be independently distributed. Dealing first with the case in which $m_{2}=0$ (the monetary authorities do not respond to the credit aggregate), inspection of the solution reported in the appendix reveals $\sigma_{r}^{2} \rightarrow 0$ as $m_{1} \rightarrow \infty$ Thus, making the level of non-borrowed reserves respond to past unanticipated movements of the real rate of interest allows fluctuations in the current real rate to be smoothed. In the Poole [1970] analysis, the monetary authorities can arbitrarily fix the nominal interest rate. Here, the monetary 
authorities can $f$ ix the real rate, but only at the value $t-1 r_{t}=\beta_{1}^{-1}\left(\beta_{0}-\bar{y}\right)$ which equates expected aggregate supply and aggregate demand.

$$
\text { From (13), } \sigma_{y}^{2}=E\left[y_{t}-{ }_{t-1} y_{t}\right]^{2}+\sigma_{\varepsilon}^{2} \text { as } m_{1}+\infty \text { Thus, a }
$$

policy of stabilizing the real rate of interest also serves to insulate real output from financial sector and aggregate supply shocks, but not from aggregate demand shocks. In addition, as

$$
\mathrm{m}_{1}+\infty, \mathrm{p}_{\mathrm{t}}-{ }_{\mathrm{t}-1} \mathrm{P}_{\mathrm{t}}+\left(1 / \alpha_{1}\right)\left(\varepsilon_{\mathrm{t}}-\mathrm{u}_{\mathrm{t}}\right)
$$

while ${ }_{t-1} p_{t}$ approaches a finite limit. Note that the financial disturbances $\psi_{t}, v_{t}$, and the $e_{i t}$ 's, have no effect on either output or prices under a fixed real rate policy. The price level is determinate under such a policy because, from (10), expected future values of non-borrowed reserves are given by $m_{0}$ and are thus finite (see McCallum [1981]).

Having demonstrated that $r_{t}$ is affected by policy in the model, the consequences of targeting on the real interest rate by the monetary authorities can now be analyzed in the context of the model solution when $m_{1}$ is finite. The general solution for $y_{t}$ is given in (13). Comparing (13) with (12) shows immediately that only in the face of agsregate demand $\left(\varepsilon_{t}\right)$ shocks is there a conflict between real 
interest rate and real output stabilization. To insulate $r_{t}$ from $\varepsilon_{t}$ requires that $1-q_{11}=0$ which, in turn, requires $m_{1}=\infty$ From (13), however, $m_{1}=\infty$ makes the coefficient on $\varepsilon$ in the equation for $y_{t}$ equal to 1. The appendix shows that stabilizing output in the face of aggregate demand shocks would require that $\dot{m}_{1}<0$, but insulating $y_{t}$ from demand stocks makes $\varepsilon_{t}$ 's coefficient in (12) equal to $\beta^{-1} A$ clear conflict exists between stabilizing $r$ and stabilizing $y$. Shifts in the IS curve cause $r$ and $y$ to move in the same direction. By affecting interest sensitive components of aggregate demand, the movement in $r$ tends to work as an automatic stabilization mechanism. If policy attempts to prevent movements in $r$, this automatic stabilization mechanism is eliminated and larger output fluctuations result.

Under a pure non-borrowed reserve rule, $\mathrm{m}_{1}=\mathrm{m}_{2}=0$ and the coefficient on $\varepsilon_{t}$ in (13) is less than one so that $y_{t}$ responds less to $\varepsilon_{t}$ than under a rule which fixes $r_{t}$. This result corresponds to that of Poole's analysis in which a money supply rule is preferred if disturbances occur to aggregate demand. The combination policy which insulates $y_{t}$ from $\varepsilon_{t}$ shocks requires the monetary authorities to reduce the current level of non-borrowed reserves if last period's real interest rate was unexpectedly high $\left(\mathrm{m}_{1}<0\right)$. 
In the face of the seven sources of snocks wodelled here, the value of $m_{1}$ which minimizes $\sigma_{y}^{2}$ will be a complicated function of the relative variances of the underlying disturbances. However, increases, for example, in the variance of the error term in the money demand equation (4) would tend to increase the $\sigma_{\mathrm{y}}^{2}$ minimizing value of $m_{1}$. Thus, greater money demand instability calls for greater deviations of the level of non-borrowed reserves from its target path in response to real interest rate movenents.

In rational expectations, equilibriun business cycle models (Barro $[1981]$ ), it is usually not optimal to atteapt to stabilize output in the face of supply shocks. Barro [1976] suggests a policy criterion which, in the present franework, would call for choosing $m_{1}$ to minimize $\underset{p}{\sigma}=E\left[p_{t}-{ }_{t-1} p_{t}\right]^{2}$. From (11),

$$
\sigma_{p}^{2}=\pi_{1}^{\prime} \Omega \pi_{1}
$$

where $\Omega=E\left(\theta_{t} \theta_{t}^{\prime}\right)$. If the monetary authorities adjust nb ${ }_{t}$ in response to real interest rate movements in order to minimize $\sigma_{p}^{2}$, it will still be the case that real output and real interest rates are completely insulated from financial sector disturbances. Suppose now the monetary authorities respond to unanticipated wovements in tank loans but not to real 1nterest rate 
movements (i.e. $m_{1}=0, m_{2} \neq 0$ ). It has already been shown that a policy of stabilizing $r_{t}$ insulates real output from all but aggregate demand shocks. If $1_{t}$ is stabilized (around $t-1{ }_{t}$ ), equations (1)-(3) can be used to derive the associated expressions for unanticipated fluctuations in $y, r$ and p. From (1)-(3) we obtain

$$
\begin{aligned}
& y_{t}-{ }_{t-1} y_{t}=-\beta_{1}\left(r_{t}-{ }_{t-1} r_{t}\right)+\varepsilon_{t} \\
& y_{t}-{ }_{t-1} y_{t}=q_{1}\left(p_{t}-{ }_{t-1} p_{t}\right)+u_{t} \\
& 1_{t}-{ }_{t-1} 1_{t}=0=p_{t}-{ }_{t-1} p_{t}-\oint_{1}\left(r_{t}-{ }_{t-1} r_{t}\right)+\delta_{2}\left(y_{t}-{ }_{t-1} y_{t}\right)+v_{t}
\end{aligned}
$$

Solving for $y_{t}-{ }_{t-1} y_{t}, r_{t}-{ }_{t-1} r_{t}$, and $p_{t}{ }_{t-1} p_{t}$ yields

$$
y_{t-1} y_{t}=\frac{\alpha_{1} \delta_{1} \varepsilon_{t}+\beta_{1} u_{t}-\alpha_{1} \beta_{t} v_{t}}{\alpha_{1} \delta+\left(1+\alpha_{1} \delta_{2}\right) \beta_{1}}
$$

$$
r_{t}-{ }_{t-1} r_{t}=\frac{\left(1+\alpha_{1} \delta_{2}\right) \varepsilon_{t}-u_{t}+\alpha_{1} v_{t}}{\alpha_{1} \delta_{1}+\left(1+\alpha_{1} \delta_{2}\right) \beta_{1}}
$$

$$
p_{t-1}-p_{t}=\frac{\delta_{1} \varepsilon_{t}-\left(\delta_{1}+\delta_{2} \beta_{1}\right) u_{t}-\beta_{1} v_{t}}{\alpha_{1} \delta+\left(1+\alpha_{1} \delta_{2}\right) \beta_{1}}
$$

Equations (17)-(19) show that a policy which eliminates unanticipated movements in a credit aggregate such as bank loans would prevent money demand and banking sector disturbances from affecting 
output, the real interest rate on loans, and the price level. For these disturbances, then, a real interest rate policy and a credit aggregate policy are equally effective in stabilizing output. As indicated by equation (17), however, aggregate supply shocks, aggregate demand shocks, and disturbances to loan demand continue to produce output and price fluctuations under a credit aggregate policy. The factors relevant for a couparison of a real rate policy and a creait aggregate policy are similar to those important in the Poole [1970] comparison of money supply and nominal interest rate policies. Under a policy which eliminates unanticipated movements in the real rate, $y_{t-1}{ }_{t-1} y_{t}=\varepsilon_{t}$. Under a credit aggregate policy, $\varepsilon_{t}$ still affects output, but the coefficient on $\varepsilon_{t}$ in (17) is less than one. Demand disturbances have a smaller effect on real output unaer a policy which prevents unanticipated fluctuations in bank loans than in real interest rates.

On the other liand, $u_{t}$ and $v_{t}$ influence $y_{t}-{ }_{t-1} y_{t}$ under a credit policy but do not under a real rate policy ${ }^{9}$ Both policies succeed in preventing money demand disturbances frow affecting either real output or the price level.

4. Summary and Conclusions

This paper utilizes an expanded aggregate rational expectations nodel which inciudes a credit market to investigate possible roles ror real interest rates ana a credit aggregate as 
intermediate targets for purposes of short-run stabilization policy. For this purpose policy is characterized by a feedback rule that permits non-borrowed reserves to deviate from a constant target in response to past fluctuations in either the real interest rate or the stock ố loans outstanaing from expected levels.

The analysis shows that stabilizing real interest rates and stabilizing output and the price level (or nominal income) in response to demand shocks is not possible. A non-borrowed reserve rule, as with the money supply rule in the original Poole analysis, is preferred in this circumstance. With pure supply or financial sector shocks, output can be stabilized by stabilizing unexpected movemencs in real interest rates, at the cost, for supply shocks, of increased price variance. Moreover, the monetary authorities can only stabilize the real interest rate at the value determined by equating aggregate supply with aggregate demand.

Stabilizing output and the price level in response to dewand shocks is also not possible by following a credit aggregate rule. However, Decause interest rates must adjust to prevent any unanticipated fluctuations in bank loans with such a rule, the contributions of demand shocks to the variance in output is less than in the case of a real interest rate rule. In contrast, stabilizing credit in response to an aggregate supply shock would not prevent output fluctuations as would a real rate rule, because the resulting movewents in interest rates have a proportionate impact on aggregate 
demand. With financial sector disturbances, other than those to loan demand, the analysis shows the equivalence of a real interest rule and a credit aggregate rule. 


\section{FOOTNOTES}

1 Financial innovation in Canada has been spurred primarily by market forces, whereas in the United States, the Depository Institutions Deregulation and Monetary Control Act of 1980 has given additional impetus to developments in financial markets.

2 The most recent example in the United States is the Super-NOW account which was introduced in early 1983. In Canada, most chartered banks now offer daily interest chequing accounts which combine features of daily interest savings and personal chequing accounts.

3 See, for example, Benavie and Froyen [1982] for an analysis of the relationship between policy variables and the money supply with a flexible deposit rate.

4 Moreover, in the United States, recently proposed bills in both Houses of Congress seek to amend the Federal Reserve Act by requiring the Federal Open Market Committee to establish targets for long-term nominal or short-term real rates of interest. For discussions of real rate targeting, see Hester [1982] and Walsh [1983].

5 See Benavie [1983] for an analysis of monetary policy when the real rate of interest enters the aggregate supply curve.

6 McCallum [1981] has shown, however, that the nominal interest rate can be used as a policy instrument to achieve a money target without leading to problems of price level indeterminacy. Turnovsky [1980] explicitly takes the view that an indeterminate expected price level is not a problem if the conditional variance is finite.

7 This differs from Woglom [1979] and Benavie [1983] who allow the monetary authorities to respond contemporaneously to the nominal rate of interest.

8 Because the error terms in (1) and (2) are assumed to be serially uncorrelated, $\left.t-2^{r} t-1=\left(\beta_{0}-\bar{y}\right) / \beta_{1}\right)$ is a constant. This would not be the case if $\varepsilon_{t}$ or $u_{t}$ were serially correlated.

9 If the objective is to minimize the variance of $\mathrm{p}_{t}{ }_{t-1} \mathrm{p}_{t}$, a comparison of (19) should be made with $\left(1 / q_{1}\right)\left(\varepsilon_{t}-u_{t}\right)$ since this is $p_{t-1}{ }_{t-1} p_{t}$ when $r_{t}{ }^{-}-1 r_{t}=0$. The coefficients of both $\varepsilon_{t}$ and $v_{t}$ in (19) are less than $1 / q_{1}$ in absolute value. 


\section{REFERENCES}

Barro, Robert J., Rational Expectations and the Role of Monetary Policy, Journal of Monetary Economics, 2 No. 1 (Jan. 1976) $1-32$.

,The Equilibrium Approach to Business Cycles, in Money, Expectations, and Business Cycles, Academic Press, 1981.

Benavie, Arthur, Optimal Monetary Pollcy under Rational Expectations with a Micro-Based Supply Function, Journal of Macroeconomics, 5, No. 2 (Spring 198\%), 149-166.

and Richard T. Froyen, Monetary Pollcy in a Model with a Federal Funds Market: Fixed versus Flexible Deposit Rates, Southern Economic Journal, 48 No. 4 (April 1982), 932-949.

- Combination Monetary Policies to Stabilize Price and Output Under Rational Expectations, Journal of Money, Credit, and Banking, 15 No. 2 (May 1983), 186-198.

Brunner, Kar1, Alex Cukierman, and Allan H. Meltzer, Stagflation, Persistent Unemployment, and the Permanence of Economic Shocks, Journal of Monetary Economics, 6 (October 1980), 467-492.

Feldstein, Martin and Laurence Summers, Inflation, Tax Rules, and the Long-Term Interest Rate, Brookings Papers on Economic Activity $(1978: 1), 61-99$.

Fischer, Stanley, Long Term Contracts, Rational Expectations, and the optimal Policy Rule, Journal of Political Economy, 85 (February 1977), $191-206$.

Friedman, Benjamin M., Targets, Instruments and Indicators of Monetary Polfcy, Journal of Monetary Economics, 1 (October 1975), 443-473.

, The Inefficiency of Short-Run Monetary Targets for Monetary Policy, Brookings Papers on Economic Activity $(1977), 293-335$.

, Monetary Policy with a Credit Aggregate in Money, Monetary Policy, and Financial Institutions, K. Brunner and A.H. Meltzer (eds) Carnegie-Rochester Conference Serles on Public Policy, Vol. 18 (Spring 1983). 
Hester, Donald, On the Adequacy of Policy Instruments and Inforwation When the Meaning of loney is Changing, American Economic Review, 72 No. 2 (May 1982), 40-44.

McCallum, Bennett T., Rational Expectations and Macroeconomic Stabilization Policy: An Overview, Journal of Money, Credit and Banking, 12 (November 1980, Pt. 2), 716-746.

, Price Level veterminacy with an Interest Rate Policy kule and Rational Expectations, Journal of Monetary Economics, 8 (iNovember 1981), 319-329.

, On Non-Uniqueness in Kational Expectations hlodels: fin Attempt at Perspective, Journal of Monetary Economics, 11 (March 1983), 139-168.

, and James G. Hoehn, Instrument Choice for Money Stock Control with Contemporaneous and Lagged Reserve Requirements, Journal Control Money, Creait, and Banking, 15 (February 1983), 96-101.

Muth, J.F., Optimal Properties of Exponentially We1ghted Forecasts, Journal of the American Statistical Association, 55 (June 1960), 299-306.

Parkin, Michael, A Comparison of Alternative Techniques of Monetary Control Under Rational Expectations, Manchester School, 46 No. 3 (September 1978), 252-287.

Poole, William, Optimal Choice of Monetary Policy Instrument in a Simple Stochastic Hacro Model, Quarterly Journal of Economics, 84 (May 1970), 197-216.

Sargent, Thomas J. and Neil Wallace, 'Rational' Expectations, the Optimal Monetary Instrument, and the Optimal Honey Supply Rule, Journal of Political Economy, 83 (April 1975), 241-254.

Shiller, kobert J., Can the Fed Control Keal Interest kates? in Rational txpectations and Economic Yolicy, Stanley Fischer (ed., ) University of Chicago Press, 1980.

Turnovsky, stephen J., The Choice of Monetary Instrument Under Alternative Forms of Price Expectations, Manchester School, 48 No. 1 (March 1980), 39-62.

Walsh, Car $\perp$ E., Should the Federal Reserve Target Real Interest Rates? Federal Reserve Bank of Kansas City Economic Review, June 1983. 
- Interest Rate Volalitity and Monetary Policy, Journal of Money, Credit, and Banking, 16 (May 1984), 133-150.

Woglom, Geoffrey, Rational Expectations and Monetary Policy in a Simple Macroeconomic Model, Quarterly Journal of Economics, 93 (Feb. 1979), 91-105. 


\section{APPENDIX}

This appendix outlines the derivation of the rational expectations solution for $p_{t}$ reported in section 2 .

Equations $(3)-(8)$ and $(10)$ can be used to eliminate $l_{t}$, $d_{t}, t r_{t}$, and $n b_{t}$, yielaing a three equation model of the financial sector which can be written as

$A \cdot 1\left[\begin{array}{lll}a_{1}+\delta_{1} & -a_{2} \\ b_{1}-\gamma_{2} & -\left(b_{2}+\gamma_{1}\right) & b_{3} \\ c_{1}+\gamma_{2} & c_{2}-\gamma_{1} & c_{3}\end{array}\right]\left[\begin{array}{l}i_{t} \\ i_{d t} \\ i_{f t}\end{array}\right]=\left[\begin{array}{c}\delta_{0}-a_{0}+\delta_{1}\left({ }_{t} p_{t+1}-p_{t}\right)+\delta_{2} y_{t}+p_{t}+v_{t}-e_{1 t} \\ \gamma_{0}-b_{0}+\gamma_{3} y_{t}+p_{t}+\psi_{t}-e_{2 t} \\ z_{t}\end{array}\right]$

where $z_{t}=\rho+\gamma_{0}-c_{0}+p_{t}+\gamma_{3} y_{t}+\psi_{t}-e_{3 t}-m_{0}+\left(m_{2}\left\{+m_{2} \& \delta-m_{1}\right)\left(r_{t-1}-t-2 r_{t-1}\right)-\right.$

$$
\mathrm{m}_{2} \xi_{2} \varepsilon_{-1}-\mathrm{m}_{2}\left(\mathrm{p}_{\mathrm{t}-1}{ }^{-}{ }_{\mathrm{t}-2} \mathrm{p}_{\mathrm{t}-1}\right)-\mathrm{m}_{2} \mathrm{v}_{\mathrm{t}-1}
$$

A.l can be solved for $i_{t}$ to yield

$$
\begin{aligned}
& \text { A.2 } i_{t}=h_{0}+\delta_{1} h_{1}\left(p_{t} p_{t+1}-p_{t}\right)+h_{2} y_{t}-m_{2} h_{3}\left(p_{t-1}-{ }_{t-2} p_{t-1}\right)+\left(h_{3}+h_{4}+h_{5}\right) p_{t} \\
& +\left(m_{2} \delta_{1}+m_{2} \beta_{1} \delta_{2}-m_{1}\right) h_{3}\left(r_{t-1}-{ }_{t-2} r_{t-1}\right)+h_{4}\left(v_{t}-e_{1 t}\right)+h_{5}\left(t-e_{2 t}\right) \\
& +h_{3}\left(\psi_{t}-e_{3 t}\right)-m_{2} h_{3} v_{t-1}-m_{2} \delta_{2} h_{3} \varepsilon_{t-1}
\end{aligned}
$$

where $h_{i}, i=0, \ldots, 5$ are functions of the parameters in A.l. Notice that the $h_{i}$ 's are independent of $\mathrm{ta}_{1}$ and $m_{2}$. Subtracting expected inflation trom A.2 gives 


$$
\begin{aligned}
\text { A.3 } & r_{t}=h_{0}+\left(\delta_{1} h_{1}-1\right)\left(p_{t+1}-p_{t}\right)+h_{2} y_{t}-m_{2} h_{3}\left(p_{t-1}-t-2 p_{t-1}\right)+\left(t_{3}+h_{4}+h_{5}\right) p_{t} \\
& +\left(m_{2} \delta_{1}+m_{2} \beta_{1}-m_{1}\right)\left(r_{t-1}-{ }_{t-2} r_{t-1}\right)+h_{4}\left(v_{t}-e_{1 t}\right)+h_{5}\left(\psi-e_{2 t}\right)+h_{3} \\
& \left(\psi_{t}-e_{3 t}-m_{2} v_{t-1}-m_{2} \delta_{2} \varepsilon_{t-1}\right) .
\end{aligned}
$$

A.3, together with (1), inplies

$$
\begin{array}{cc}
\text { A.4 } & r_{t}-{ }_{t-1} r_{t}=\left(1+\beta_{1} h_{2}\right)^{-1}\left[\left(\xi_{1} h_{1}-1\right)\left({ }_{t} p_{t+1}-{ }_{t-1} p_{t+1}-p_{t}+{ }_{t-1} p_{t}\right)+h_{2} \varepsilon_{t}+\right. \\
& \left.\left(h_{3}+h_{4}+h_{5}\right)\left(p_{t}-{ }_{t-1} p_{t}\right)+h_{4}\left(v_{t}-e_{1 t}\right)+h_{5}\left(\psi-e_{2 t}\right)+h_{3}\left(\psi-e_{3 t}\right)\right]
\end{array}
$$

Lag A.4 one period and substitute the result, together with (1), into A.3 to produce

$$
\begin{aligned}
\text { A.5 } & \left(1+\beta_{1} h_{2}\right) r_{t}=h_{0}+\left(\delta_{1} h_{1}-1\right)\left(p_{t} p_{t+1}-p_{t}\right)+h_{2} \varepsilon_{t}-m_{2} h_{3}\left(p_{t-1}-{ }_{t-2} p_{t-1}\right) \\
& +\left(h_{3}+h_{4}+h_{5}\right) p_{t}+\left(m_{2} \delta_{1}+m_{2} \beta_{1} \delta_{2}-m_{1}\right)\left(1+\beta_{1} h_{2}\right)^{-1}\left[\left(\delta_{1} h_{1}-1\right)\left(t_{t-1} p_{t}-{ }_{t-2} p_{t}\right)\right. \\
& +\left(1-\delta_{1} h_{1}\right)\left(p_{t-1}-{ }_{t-2} p_{t-1}\right)+h_{2} \varepsilon_{t-1}+\left(h_{3}+h_{4}+n_{5}\right)\left(p_{t-1}-t_{t-2} p_{t-1}\right)+h_{4} \\
& \left.\left(v_{t-1}-e_{1 t-1}\right)+h_{5}\left(\psi_{t-1}-e_{2 t-1}\right)+h_{3}\left(\psi_{t-1}-e_{3 t-1}\right)\right]+h_{4}\left(v_{t}-e_{1 t}\right)+h_{5}\left(\psi_{t}-e_{2 t}\right) \\
& +h_{3}\left(\psi_{t}-e_{3 t}-\mathrm{m}_{2} v_{t-1}-m_{2} \delta_{2} \varepsilon_{t-1}\right)
\end{aligned}
$$

From (1) and (2),

$$
\text { A.6 } \quad B_{1} r_{t}=B_{0}-\bar{y}-\alpha_{1}\left(P_{t}-{ }_{t-1} P_{t}\right)+\varepsilon_{t}-u_{t}
$$


Using A.6 to eliminate $r_{t}$ from A.5 yields the following equation in the price level and expectations of the price level.

A.7 $\left[\beta_{1}\left(h_{3}+h_{4}+h_{5}\right)+\alpha_{1}\left(1+\beta_{1} h_{2}\right) p_{t}=n_{0}+\beta_{1}\left(1-\delta_{1} h_{1}\right)\left({ }_{t} p_{t+1}-p_{t}\right)\right.$

$+\beta_{1}\left(1-\xi_{1} h_{1}\right)\left(1+\beta_{1} h_{2}\right)^{-1}\left(m_{2} \oint_{1}+m_{2} \xi_{2}-m_{1}\right)\left(t-1 p_{t}-{ }_{t-2} p_{t}\right)+$

$\beta_{1}\left[m_{2} h_{3}-\left(1+\beta_{1} h_{2}\right)^{-1}\left(m_{2} \delta_{1}+m_{2} \beta_{1} \delta_{2}-m_{1}\right)\left(1-\delta_{1} h_{1}+h_{3}+h_{4}+h_{5}\right)\right]\left(p_{t-1}-t-2 p_{t-1}\right)$

$+\left[\left(1+\beta_{1} h_{2}\right)+\beta_{1} h_{2}\right] \varepsilon_{t}-\left(1+\beta_{1} h_{1}\right) u_{t}-\beta_{1}\left[h_{4}\left(r_{t}-e_{1 t}\right)+h_{5}\right.$

$\left(\psi_{t}-e_{2 t}\right)+h_{3}\left(\psi_{t}-e_{3 t}\right)+\beta_{1}\left(1+\beta_{1} n_{2}\right)^{-1}\left(m_{2} \oint+m_{2} \delta_{2} \xi^{-m_{1}}\right)\left[h_{2} \varepsilon_{t-1}\right.$

$\left.+h_{4}\left(v_{t-1}-e_{1 t-1}\right)+h_{5}\left(\psi_{t-1}-e_{2 t-1}\right)+h_{3}\left(\psi_{t-1}-e_{3 t-1}\right)\right]+\left\{h_{3} m_{2}\right.$

$\left[v_{t-1}+\delta_{2} \varepsilon_{t-1}\right]$

where $n_{0}$ is a constant term.

Equation (A.7) can be solved for $p_{t}$ by use of the method of undetermined coefficients. The hypothesized trial solution is of the form

A.8 $p_{t}=\pi_{0}+\pi_{1}^{\prime} \theta_{t}+\pi_{2}^{\prime} \theta_{t-1}$

where $\pi_{i}^{\prime}=\left(\pi_{i l}, \pi_{i 2}, \pi_{i 3}, \ldots \pi_{i 7}\right)$ and $\theta_{t}^{\prime}=\left(\varepsilon_{t}, u_{t}, v_{t}, e_{t}, e_{1 t}, e_{2 t}\right.$, $\mathrm{e}_{3 t}$ ). Substituting A.8 into A.7, after using A.8 to evaluate the 
expectations terms appearing in A.7, and equating coefficients on each side leads to the following set of restrictions on $\pi_{0}, \pi_{1}$ and $\pi_{2}$ :

$$
\begin{aligned}
& \kappa \pi_{0}=n_{0} \\
& k \pi_{11}=\beta_{1}\left(1-\delta_{1} h_{1}\right)\left(\pi_{21}-\pi_{11}\right)+\left(1+\beta_{1} h_{1}\right)-\beta_{1} h_{2} \\
& k \pi_{12}=\beta_{1}\left(1-\delta_{1} h_{1}\right)\left(\pi_{22}-\pi_{12}\right)-\left(1+\beta_{1} h_{1}\right) \\
& k \pi_{13}=\beta_{1}\left(1-\delta_{1} h_{1}\right)\left(\left(\pi_{23}-\pi_{13}\right)-\beta_{1} h_{4}\right. \\
& k \pi_{14}=\beta_{1}\left(1-\delta_{1} h_{1}\right)\left(\pi_{24}-\pi_{14}\right)-\beta_{1}\left(h_{3}+h_{5}\right) \\
& k \pi_{15}=\beta_{1}\left(1-\delta_{1} h_{1}\right)\left(\pi_{25}-\pi_{15}\right)+\beta_{1} h_{4} \\
& K \pi_{16}=\beta_{1}\left(1-\delta_{1} h_{1}\right)\left(\pi_{26}-\pi_{16}\right)+\beta_{1} h_{5} \\
& \kappa \pi_{17}=\beta_{1}\left(1-\delta_{1} h_{1}\right)\left(\pi_{27}-\pi_{17}\right)+\beta_{1} h_{3} \\
& k \pi_{21}=-\beta_{1}\left(1-\delta_{1} h_{1}\right) \pi_{21}+\beta_{1}\left(1-\xi_{1} h_{1}\right)\left(1+\beta_{1} h_{2}\right)^{-1} M_{21} \\
& +\beta_{1} Q \pi_{11}-\beta_{1}\left(1+\beta_{1} h_{2}\right)^{-1} M h_{2}+\beta_{1} h_{3} m_{2} \delta_{2} \\
& \kappa \pi_{22}=-\beta_{1}\left(1-\delta_{1} h_{1}\right) \pi_{22}+\beta_{1}\left(1-\delta_{1} h_{1}\right)\left(1+\beta_{1} h_{2}\right)^{-1} M \pi_{22}+\beta_{1} Q \pi_{12} \\
& k \pi_{23}=-\beta_{1}\left(1-\delta_{1} h_{1}\right) \pi_{23}+\beta_{1}\left(1-\delta_{1} h_{1}\right)\left(1+\beta_{1} h_{2}\right)^{-1} M_{23}+\beta_{1}
\end{aligned}
$$


$-26-$

$$
\begin{aligned}
& Q \pi_{13}-\beta_{1}\left(1+\beta_{1} h_{2}\right)^{-1} M_{4}+\beta_{1} h_{3} m_{2} \\
& \kappa \pi_{24}=-\beta_{1}\left(1-\oint_{1} h_{1}\right) \pi_{24}+\beta_{1}\left(1-\oint_{1} h_{1}\right)\left(1+\beta_{1} h_{2}\right)^{-1} M \pi_{24} \\
& +\beta_{1} Q \pi_{14}-\beta_{1}\left(1+\beta_{1} h_{2}\right)^{-1} M\left(h_{3}+h_{5}\right) \\
& \kappa \pi_{25}=-\beta_{1}\left(1-\xi_{1} h_{1}\right) \pi_{25}+\beta_{1}\left(1-\xi_{1} h_{1}\right)\left(1+\xi_{1} h_{2}\right)^{-1} M \pi_{25}+ \\
& \beta_{1} Q \pi_{15}+\beta_{1}\left(1+\beta_{1} h_{2}\right)^{-1} M_{4} \\
& \kappa \pi_{26}=-\beta_{1}\left(1-\delta_{1} h_{1}\right) \pi_{26}+\beta_{1}\left(1-\delta_{1} h_{1}\right)\left(1+\beta_{1} h_{2}\right)^{-1} M \pi_{26}+\beta_{1} Q \pi_{16} \\
& +\beta_{1}\left(1+\beta_{1} h_{2}\right)^{-1} \mathrm{Mh}_{5} \\
& \kappa \pi_{27}=-\beta_{1}\left(1-\delta_{1} h_{1}\right) \pi_{27}+\beta_{1}\left(1-\delta_{1} h_{1}\right)\left(1+\beta_{1} h_{2}\right)^{-1} M_{27}+ \\
& \beta_{1} Q \pi_{17}+\beta_{1}\left(1+\beta_{1} h_{2}\right)^{-1} M h_{3} \\
& \text { where } k=\beta_{1}\left(h_{3}+h_{4}+h_{5}\right)+\alpha_{1}\left(1+\beta_{1} h_{2}\right) \\
& Q=\beta_{1}\left[m_{2} h_{3}-\left(1+\beta_{1} h_{2}\right)^{-1} M\left(1-\oint_{1} h_{1}+h_{3}+h_{4}+h_{5}\right)\right] \\
& \text { and } \quad M=m_{2}\left(\delta_{1}+\beta_{1} \delta_{2}\right)-m_{1}
\end{aligned}
$$


These equations can be solved in a pairwise fashion for $\pi_{1 i}, \pi_{2 i}, i=1, \ldots, 7$. For example, the equations for $\pi_{11}$ and $\pi_{21}$ can be solved with $\mathrm{m}_{2}=0$ to varify that $\lim _{1} \mathrm{~m}_{+\infty} \pi_{11}=1 / \alpha$. Hence, $1-a_{11}=0$ as asserted in the text. Note that $\pi_{0}=n_{0} / k$ is independent of $m_{1}$ and $m_{2}$ so that the price level is well determined. 